\title{
Laminarin from Seaweed (Laminaria japonica) Inhibits Hepatocellular Carcinoma Through Upregulating Senescence Marker Protein-30
}

\author{
Lin Tian, ${ }^{1,2,{ }^{*}}$ Chun-Mei Li, ${ }^{1,3,{ }^{*}}$ Yan-Fei Li, ${ }^{1}$ Tian-Ming Huang, ${ }^{1}$ Nai-Xia Chao, \\ Guo-Rong Luo, ${ }^{1,4}$ and Fa-Rong Mo $\mathrm{Mo}^{1,4}$
}

\begin{abstract}
Objective: This study aimed at investigating the specific roles of laminarin from seaweed (Laminaria japonica) in hepatocellular carcinoma (HCC) and its potential mechanisms related to senescence marker protein-30 (SMP-30).

Materials and Methods: Human HCC cell lines, including Bel-7404 and HepG2, were incubated with different concentrations of laminarin $(0,5,15,25,35$, and $45 \mathrm{mg} / \mathrm{mL})$. The cell viability and apoptosis rates were detected by WST-8 cell proliferation assay and flow cytometry, respectively. Hepa 1-6 tumor-bearing mice were injected with different concentrations of laminarin $(400,800$, and $1200 \mathrm{mg} / \mathrm{kg} \cdot \mathrm{d})$, and tumor volume and weight were measured. The expression of SMP-30 was detected in laminarin-treated Bel-7404 and HepG2 HCC cells and LO2 normal liver cells by quantitative real-time PCR and Western blotting.

Results: The treatment with laminarin $(48 \mathrm{~h})$ significantly decreased the viability and increased the apoptosis rates of Bel-7404 and HepG2 cells in a dose-dependent manner. The injection of laminarin also significantly decreased the tumor volumes (beginning on the 10th day) and tumor weights ( $30 \mathrm{~d}$ post-injection) of mice in a dose-dependent manner. In addition, the treatment with laminarin $(35 \mathrm{mg} / \mathrm{mL}$ for $48 \mathrm{~h})$ significantly upregulated SMP-30 in Bel-7404 and HepG2 cells but not in LO2 cells.

Conclusion: Laminarin inhibited the proliferation of Bel-7404 and HepG2 cells and inhibited the growth of tumors in Hepa 1-6 tumor-bearing mice by upregulating SMP-30.
\end{abstract}

Keywords: antitumor, apoptosis, hepatocellular carcinoma, laminarin, proliferation, senescence marker protein-30

\section{Introduction}

H epatocellular carcinoma (HCC) is the fifth most common cancer in the world, accounting for $70 \%-85 \%$ of primary liver cancer. ${ }^{1,2}$ As a fatal malignant tumor of the liver, HCC is the third leading cause of cancer-related death worldwide. ${ }^{3}$ In clinical practice, the treatment of HCC mainly relies on surgical resection, especially for patients at an early stage. ${ }^{4}$ Since more than half of HCC patients are diagnosed at an advanced stage, ${ }^{5}$ adjuvant therapeutic strategies, including chemotherapy and radiotherapy, provide great therapeutic potential for HCC. ${ }^{6}$ However, the prognosis of HCC patients remains poor due to tumor metastasis and recurrence, as well as drug resistance and low therapeutic specificity. Therefore, research into novel therapeutic strategies for $\mathrm{HCC}$ is urgently needed.

Due to the adverse effects of and drug resistance to conventional antitumor drugs, natural bioactive substances

\footnotetext{
${ }^{1}$ School of Preclinical Medicine, Guangxi Medical University, Nanning, China.

${ }^{2}$ Science and Technology College, Hubei Minzu University, Enshi, China.

${ }^{3}$ Laboratory of Hepatobiliary and Pancreatic Surgery, Affiliated Hospital of Guilin Medical University, Guilin, China.

${ }^{4}$ Guangxi Colleges and Universities Key Laboratory of Human Development and Disease Research, Guangxi Medical University, Nanning, China.

$*$ These authors contributed equally to this work.
}

Address correspondence to: Fa-Rong Mo; School of Preclinical Medicine, Guangxi Medical University; Shuangyong Road 22, Nanning 530021, China E-mail: farongmo@126.com

(C) Lin Tian et al. 2020; Published by Mary Ann Liebert, Inc. This Open Access article is distributed under the terms of the Creative Commons Attribution Noncommercial License (http://creativecommons.org/licenses/by-nc/4.0/) which permits any noncommercial use, distribution, and reproduction in any medium, provided the original author(s) and the source are cited. 
emerge as potential sources of antitumor drugs with low toxicity. ${ }^{7}$ Laminarin (1-3,1-6-glucan) is a polysaccharide in seaweed (Laminaria japonica) that is composed of 1,3- and 1,6-glycosidic bond-linked $\beta$-D-glucopyranose molecules. Laminarin exhibits bioactivities similar to those of $\beta$-glucan, such as immune-enhancing, antioxidant, anti-aging, and antitumor properties. ${ }^{8}$ Until now, the antitumor roles of laminarin have mainly been identified in colorectal carcinoma (CC). For example, laminarin induces the apoptosis of LOVO human colon cancer cells through a mitochondrial pathway. ${ }^{9}$ Laminarin induces the apoptosis of HT-29 cells and increases the percentage of cells in the sub-G1 and G2/ $\mathrm{M}$ phases. ${ }^{10}$ Laminarin inhibits the colony formation of CC DLD-1 cells and increases the 1,6-linked glucose residue content to enhance the antitumor effect. ${ }^{11}$ However, related studies on the specific roles of laminarin in HCC are still limited.

Senescence marker protein-30 (SMP-30) is a $34 \mathrm{kDa}$ cytosolic marker of aging that decreases with age. ${ }^{12}$ SMP-30 is also known as regucalcin, which acts to protect cells from apoptosis by enhancing plasma membrane $\mathrm{Ca}(2+)$ pump activity. ${ }^{13}$ Moreover, SMP-30 serves as a prognostic marker and a potential therapeutic target for HCC. ${ }^{14,15}$ It has been reported that SMP-30 expression is significantly reduced in HCC tissues compared with in adjacent non-tumor tissues and is negatively associated with the tumor size, TNM stage, and poor survival of HCC patients. ${ }^{14}$ Silencing of SMP-30 promotes the proliferation and invasion of HepG2 cells. ${ }^{15}$

Based on the antiaging effect of laminarin, we speculated that laminarin may upregulate SMP-30 expression. However, whether the regulatory roles of laminarin in $\mathrm{HCC}$ are related to SMP-30 is still unclear. In this study, the specific effects of laminarin on the proliferation and apoptosis of Bel-7404 and HepG2 cells and on the tumor growth in Hepa 1-6 tumor-bearing mice were evaluated. Our findings may reveal the antitumor effects of laminarin on HCC both in vitro and in vivo to provide a novel agent for the treatment of HCC.

\section{Materials and Methods}

\section{Cell culture}

Human HCC cell lines Bel-7404 and HepG2, mouse HCC cell line Hepa 1-6, and normal liver cell line LO2 were purchased from the Cell Bank of Chinese Academy of Medical Sciences (Beijing, China). Cells were maintained in Dulbecco's modified Eagle's medium (DMEM) (HyClone, Los Angeles, CA) containing 10\% fetal bovine serum (FBS) (Dojindo, Tokyo, Japan), $100 \mathrm{U} / \mathrm{mL}$ penicillin, and $100 \mu \mathrm{g} / \mathrm{mL}$ streptomycin. The cells were cultured in an incubator at $37^{\circ} \mathrm{C}$ with $5 \% \mathrm{CO}_{2}$ and $95 \%$ humidity. Cells in the logarithmic growth phase were used for further assays.

\section{Cell treatments}

Laminarin was purchased from Shanghai Jinsui BioTechnology Co., Ltd. (Shanghai, China). Bel-7404 and HepG2 cells were seeded in 96-well plates at a density of $5 \times 10^{3}$ cells/well. After $24 \mathrm{~h}$ of culturing, cells were incubated with DMEM containing different concentrations of laminarin $(5,15,25,35$, and $45 \mathrm{mg} / \mathrm{mL})$. DMEM containing $0 \mathrm{mg} / \mathrm{mL}$ laminarin was used as the control.

\section{WST-8 cell proliferation assay}

Cell viability was detected in Bel-7404 and HepG2 cells at 24,48 , and $72 \mathrm{~h}$ post-treatment by using the CCK-8 Assay Kit (Dojindo) in accordance with the manufacturer's instructions. Simply, cells were seeded in 96-well plates at a density of $2 \times 10^{3}$ cells/well and incubated with CCK-8 solution for $2 \mathrm{~h}$ at $37^{\circ} \mathrm{C}$. The optical density (OD) at $450 \mathrm{~nm}$ was detected by a microplate reader (Synergy H1; Biotek, Winooski, VT).

\section{Cell apoptosis assay}

The apoptosis of Bel-7404 and HepG2 cells was detected by flow cytometry at $48 \mathrm{~h}$ post-treatment. Simply, cells were seeded in 96-well plates at a density of $4 \times 10^{5}$ cells/well, and they were then incubated with annexin V-fluorescein isothiocyanate (Keygen, Nanjing, China) and propidium iodide for $10 \mathrm{~min}$ at $25^{\circ} \mathrm{C}$ in the dark. The apoptosis rate was analyzed on a flow cytometer (BD, Franklin Lakes, NJ).

\section{Establishment of a tumor model in mice}

C57BL/6 mice that were 4-6 weeks old and $20 \pm 2 \mathrm{~g}$ in weight were purchased from Beijing Huafukang Biotechnology Co., Ltd. (Beijing, China). Mice were fed in a specific pathogen-free animal room at $22^{\circ} \mathrm{C}-25^{\circ} \mathrm{C}$ with free access to water and food. Hepa $1-6$ cells $\left(1 \times 10^{7}\right)$ were subcutaneously injected into mice at the anterior right subaxillary $(N=24)$. When the tumors grew to a volume of $200 \mathrm{~mm}^{3}$, mice were injected with different concentrations of laminarin (400, 800, and $1200 \mathrm{mg} / \mathrm{kg} \cdot \mathrm{d}$ ) through the caudal vein. Mice injected with an equal volume of physiological saline were considered as the control $(0 \mathrm{mg} / \mathrm{kg} \cdot \mathrm{d})$. The tumor volume was measured every $5 \mathrm{~d}$, and the tumor weight was measured at $30 \mathrm{~d}$ postinjection. The inhibition rate was calculated as (1 - tumor weight-experimental group/tumor weight-control group) $\times$ $100 \%$. All animal experiments were performed in accordance with the guidelines of the Public Health Service Policy on the Care and Use of Laboratory Animals.

\section{Quantitative real-time PCR}

Total RNA was extracted from cells by using an RNA extraction kit (TaKaRa, Dalian, China) and reversetranscribed by using a cDNA synthesis kit (TaKaRa) in accordance with the manufacturer's instructions. Quantitative real-time PCR (qPCR) was performed on a LightCycler PCR instrument (Roche, Basel, Switzerland) by using the TB Green RT-PCR kit with specific primers (SMP-30-F, 5'GCAACCTGAAGCTGGTGGAA-3'; SMP-30-R, 5'-GACC TGTCCTCATCCCGCATA-3'). GAPDH was used as an internal control (GAPDH-F, 5'-CCATCTACGAGGGCTA CGC-3'; GAPDH-R, 5'-GGAAGGAGGGCTGGAACA-3'). The PCR protocol included $95^{\circ} \mathrm{C}$ for $10 \mathrm{~min}, 40$ cycles of $95^{\circ} \mathrm{C}$ for $5 \mathrm{~s}$ and $60^{\circ} \mathrm{C}$ for $30 \mathrm{~s}$, and a final extension at $72^{\circ} \mathrm{C}$ for $3 \mathrm{~min}$. Relative expression of SMP-30 was calculated with the $2^{-\Delta \Delta \mathrm{Ct}}$ method.

\section{Western blot analysis}

Total proteins were isolated from cells by using a total protein extraction kit (Vazyme, Nanjing, China), and they 
were quantified by using a BCA protein assay kit (Vazyme). The proteins were separated by $10 \%$ sodium dodecyl sulfatepolyacrylamide gel electrophoresis and transferred to a polyvinylidene fluoride membrane (BD). The membrane was blocked with $5 \%$ skim milk for $3 \mathrm{~h}$ and incubated with specific primary antibodies, including anti-SMP-30 (1:200; Abcam, Cambridge, England) and anti- $\beta$-actin (1:5000; Fdbio, Hangzhou, China) overnight at $4^{\circ} \mathrm{C}$. Then, the membrane was incubated with horseradish peroxidase-conjugated secondary antibody (1:5000; Fdbio) for $2 \mathrm{~h}$ at $25^{\circ} \mathrm{C}$. The protein bands were visualized by using an enhanced chemiluminescence kit (Fdbio) and quantified by using a gel imaging analysis system (Olympus, Tokyo, Japan).

\section{Statistical analysis}

Statistical analysis was performed by using SPSS version 13.0 (SPSS, Inc., Chicago, IL). Experiments were performed at least in triplicate, and the data were expressed as the mean \pm standard deviation. Comparison between different groups was determined by $t$-test for two groups and one-way ANOVA for more than two groups. A $p$-value less than 0.05 was considered statistically significant.

\section{Results}

\section{Laminarin inhibited the proliferation of HCC cells}

The viability (OD at $450 \mathrm{~nm}$ ) of Bel-7404 and HepG2 cells was detected by WST-8 cell proliferation assay. As shown in Figure 1, the treatment with laminarin (48 h) significantly decreased the viability of Bel-7404 cells in a dosedependent manner until it reached the lowest point $35 \mathrm{mg} / \mathrm{mL}$ $(p<0.05)$ (Fig. 1A). In addition, Bel-7404 cells treated with $35 \mathrm{mg} / \mathrm{mL}$ laminarin exhibited significantly lower cell viability than those without treatment $(0 \mathrm{mg} / \mathrm{mL})$ at 24,48 , and $72 \mathrm{~h}$ post-treatment $(p<0.05)$ (Fig. 1B). The viability of Bel-7404 cells treated with $35 \mathrm{mg} / \mathrm{mL}$ laminarin for $48 \mathrm{~h}$ was only
$46.20 \%$ of that of cells without treatment $(0 \mathrm{mg} / \mathrm{mL})$. Results consistent with Bel-7404 cells were also observed in HepG2 cells $(p<0.05)$ (Fig. 1C, D). The viability of HepG2 cells treated with $35 \mathrm{mg} / \mathrm{mL}$ laminarin for $48 \mathrm{~h}$ was only $42.85 \%$ of that of cells without treatment $(0 \mathrm{mg} / \mathrm{mL})$.

\section{Laminarin promoted the apoptosis of HCC cells}

The apoptosis of Bel-7404 and HepG2 cells was detected by flow cytometry. It showed that the Bel-7404 cells were mainly in the late phase of apoptosis and the HepG2 cells were mainly in the early phase of apoptosis (Fig. 2A, B). The treatment with laminarin $(48 \mathrm{~h})$ significantly increased the apoptosis rate of Bel-7404 cells in a dose-dependent manner $(p<0.05)$ (Fig. 2C). The apoptosis rate of Bel-7404 cells treated with $35 \mathrm{mg} / \mathrm{mL}$ laminarin for $48 \mathrm{~h}$ was $\sim 2.72$ times higher than the rate in those without treatment $(0 \mathrm{mg} / \mathrm{mL})$. Results consistent with Bel-7404 cells were also observed in HepG2 cells $(p<0.05)$ (Fig. 2D). The apoptosis rate of HepG2 cells treated with $35 \mathrm{mg} / \mathrm{mL}$ laminarin for $48 \mathrm{~h}$ was $\sim 8.18$ times higher than that of those without treatment $(0 \mathrm{mg} / \mathrm{mL})$.

\section{Laminarin promoted tumor growth in mice}

The antitumor effects of laminarin in HCC were further evaluated in Hepa 1-6 tumor-bearing mice. As shown in Figure 3A, the tumor volume of mice injected with Hepa 16 cells significantly increased in a time-dependent manner $(p<0.05)$. The treatment with laminarin significantly decreased the tumor volume in a dose-dependent manner beginning on the 10th day $(p<0.05)$ (Fig. 3A). After injection for $30 \mathrm{~d}$, the tumor weights of mice were significantly decreased by laminarin treatment in a dose-dependent manner $(p<0.05)$ (Fig. 3B). The tumor growth inhibition rates of 400,800 , and $1200 \mathrm{mg} / \mathrm{kg} \cdot \mathrm{d}$ laminarin were $21.38 \%$, $56.60 \%$, and $67.92 \%$, respectively (Fig. 3C). In addition, after the injections were given for $30 \mathrm{~d}$, body weight was significantly lower in mice injected with $1200 \mathrm{mg} / \mathrm{kg} \cdot \mathrm{d}$
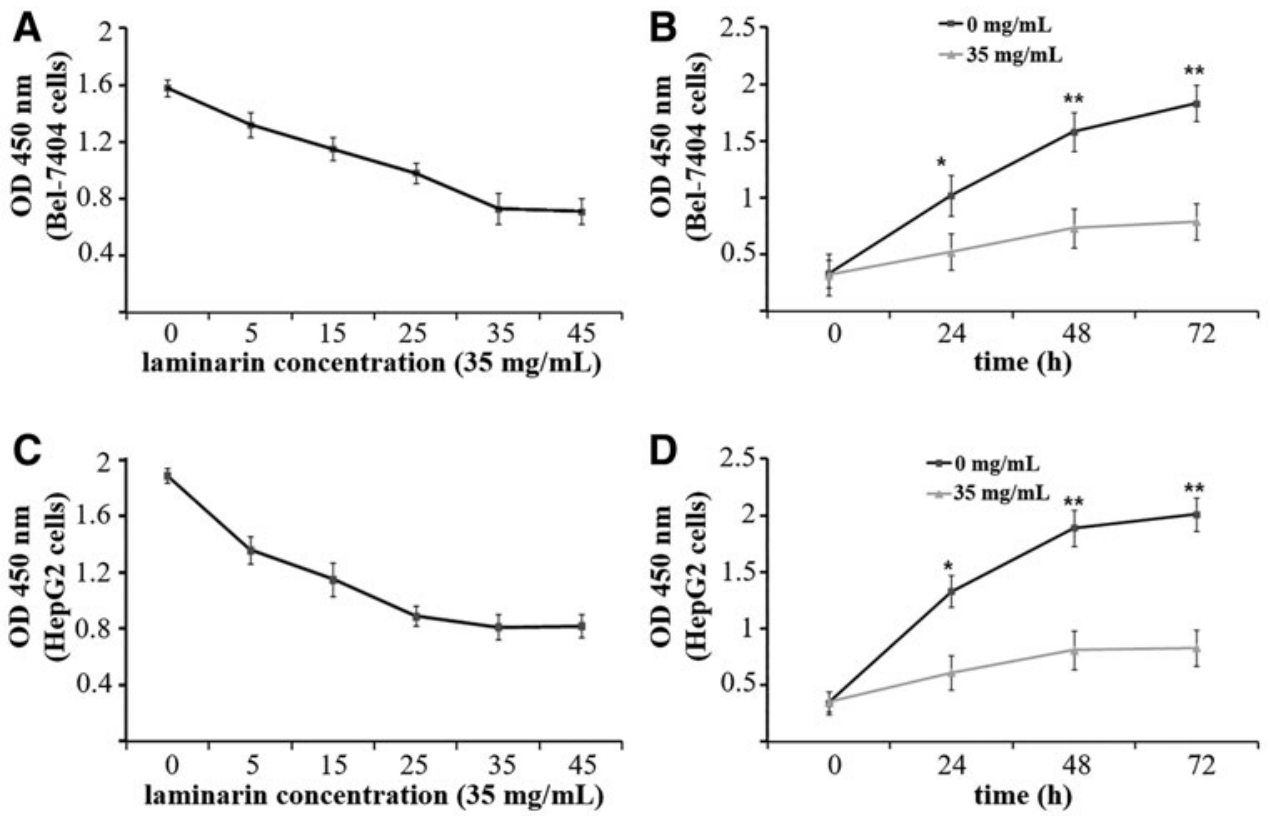

FIG. 1. The viability (OD at $450 \mathrm{~nm}$ ) of Bel-7404 and HepG2 cells detected by WST-8 cell proliferation assay. (A) Bel-7404 cells treated with laminarin at different concentrations for 48 h. (B) Bel-7404 cells treated with $35 \mathrm{mg} / \mathrm{mL}$ laminarin for different times. (C) HepG2 cells treated with laminarin at different concentrations for 48 h. (D) HepG2 cells treated with $35 \mathrm{mg} / \mathrm{mL}$ laminarin for different times. * and $* *$ Represent significantly different at $p<0.05$ and $p<0.01$ when compared with $35 \mathrm{mg} / \mathrm{mL}$ laminarin, respectively. 


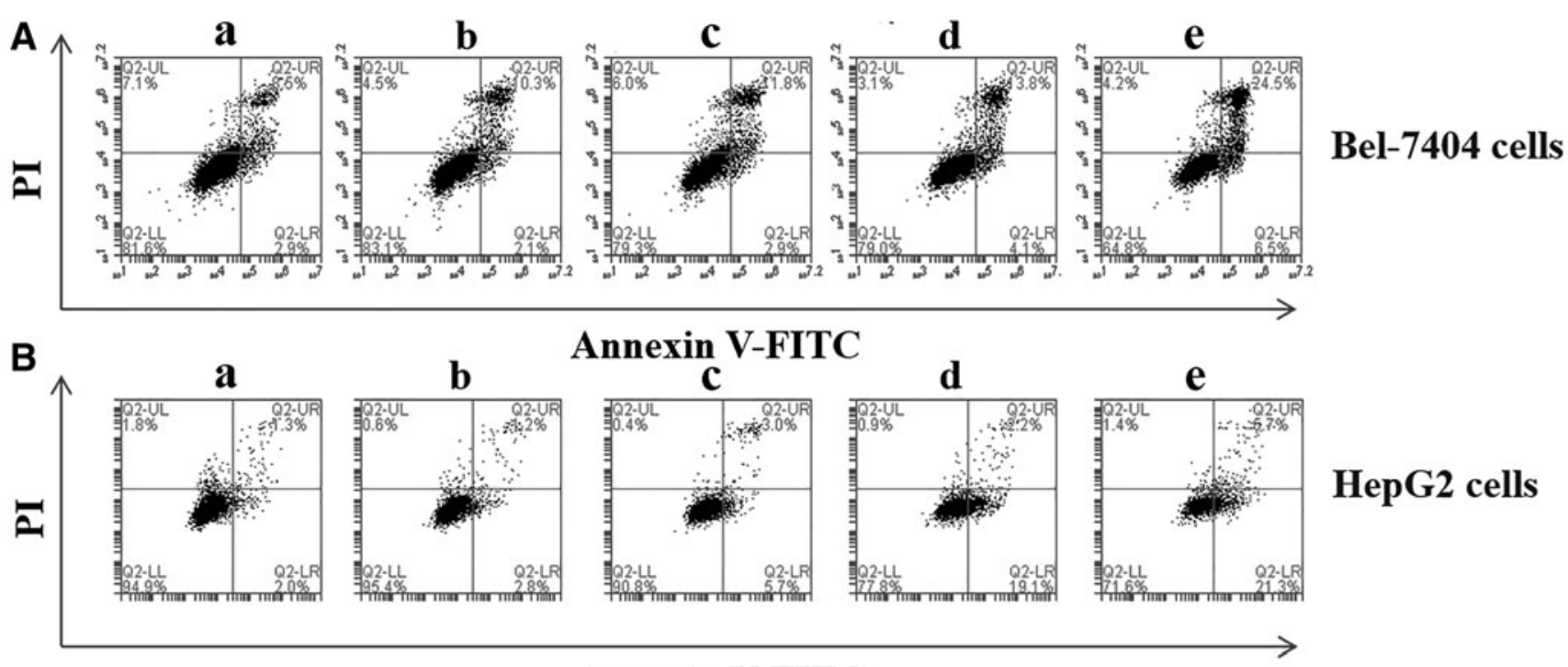

Annexin V-FITC
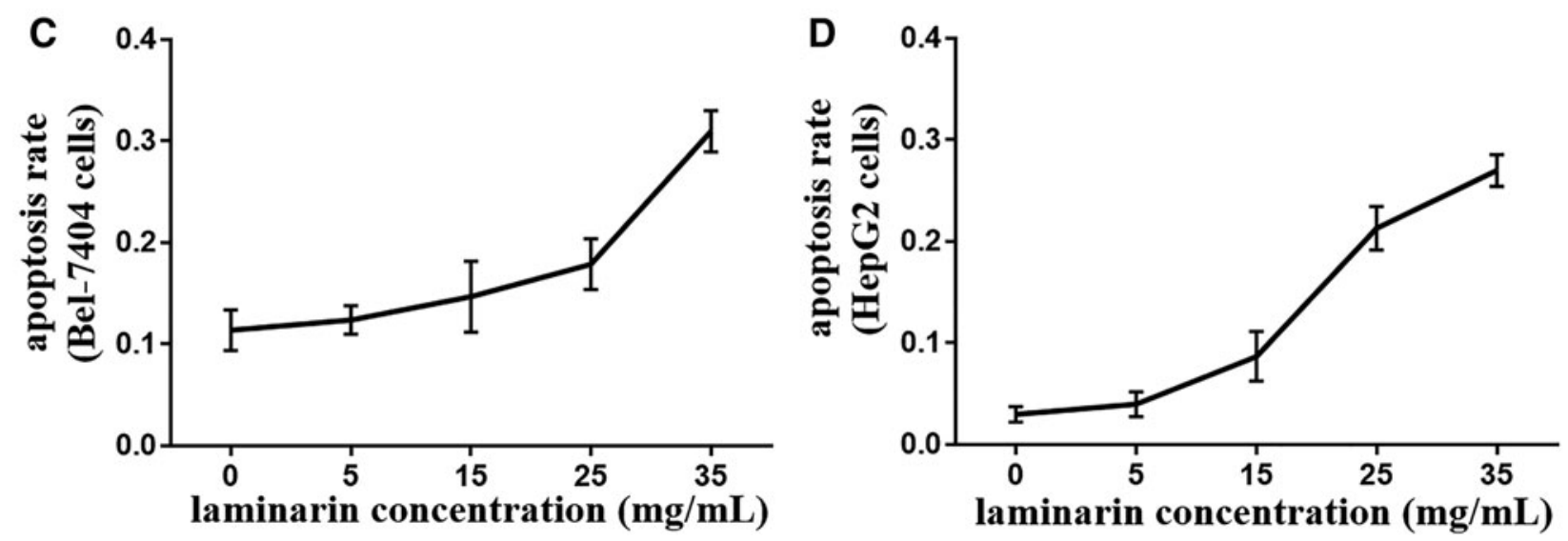

FIG. 2. The apoptosis of Bel-7404 and HepG2 cells detected by flow cytometry. (A) Flow cytometry graphs of Bel-7404 cells treated with laminarin at different concentrations for $48 \mathrm{~h}$. (B) Flow cytometry graphs of HepG2 cells treated with laminarin at different concentrations for $48 \mathrm{~h}$. (C) Apoptosis rate of Bel-7404 cells treated with laminarin at different concentrations for $48 \mathrm{~h}$. (D) Apoptosis rate of HepG2 cells treated with laminarin at different concentrations for $48 \mathrm{~h}$. The letters a, b, c, d, and e represent $0,5,15,25$, and $35 \mathrm{mg} / \mathrm{mL}$ laminarin, respectively.

laminarin than it was in mice injected with 0,400 , and $800 \mathrm{mg} / \mathrm{kg} \cdot \mathrm{d}$ laminarin $(p<0.05)$. No significant differences in body weight were observed among mice injected with 0 , 400 , and $800 \mathrm{mg} / \mathrm{kg} \cdot \mathrm{d}$ laminarin (Fig. 3D).

\section{Laminarin upregulated SMP-30 in HCC cells}

The expression of SMP-30, a senescence marker, was detected in HCC and normal liver cells. As shown in Figure 4, the expression of SMP-30 was significantly lower in Bel-7404 and HepG2 cells than in LO2 cells at both the mRNA and protein levels $(p<0.05)$. Notably, the expression of SMP-30 was significantly increased by the treatment with $35 \mathrm{mg} / \mathrm{mL}$ laminarin for $48 \mathrm{~h}$ in Bel-7404 and HepG2 cells at both the mRNA and protein levels $(p<0.05)$. The expression of SMP30 was not significantly influenced by laminarin treatment in LO2 cells (Fig. 4). It showed that the effect of laminarin to upregulate SMP-30 in Bel-7404 cells is more obvious.

\section{Discussion}

HCC is a common liver cancer that seriously affects the quality of life of patients. ${ }^{16}$ Since the toxicity of and tolerance to conventional antitumor drugs greatly limit the treatment outcomes of HCC, natural bioactive substances have become a substitute with great therapeutic potential. ${ }^{7}$ Until now, obvious antitumor effects in HCC have been identified in diverse natural bioactive substances, such as gambogic acid, tea catechins, genistein, berberine, resveratrol, curcumin, artemisinin, and matrine. ${ }^{17}$ In this study, the antitumor roles of laminarin, a polysaccharide in seaweed, were evaluated. We found that laminarin significantly inhibited the proliferation and promoted the apoptosis of Bel-7404 and HepG2 cells in vitro. Further, laminarin also significantly inhibited tumor growth in Hepa 1-6 tumor-bearing mice.

$\beta$-glucan is a group of $\beta$-D-glucose polysaccharides that exhibits obvious biological activity against chronic diseases, such as diabetes mellitus, improper digestion, and cancer. 

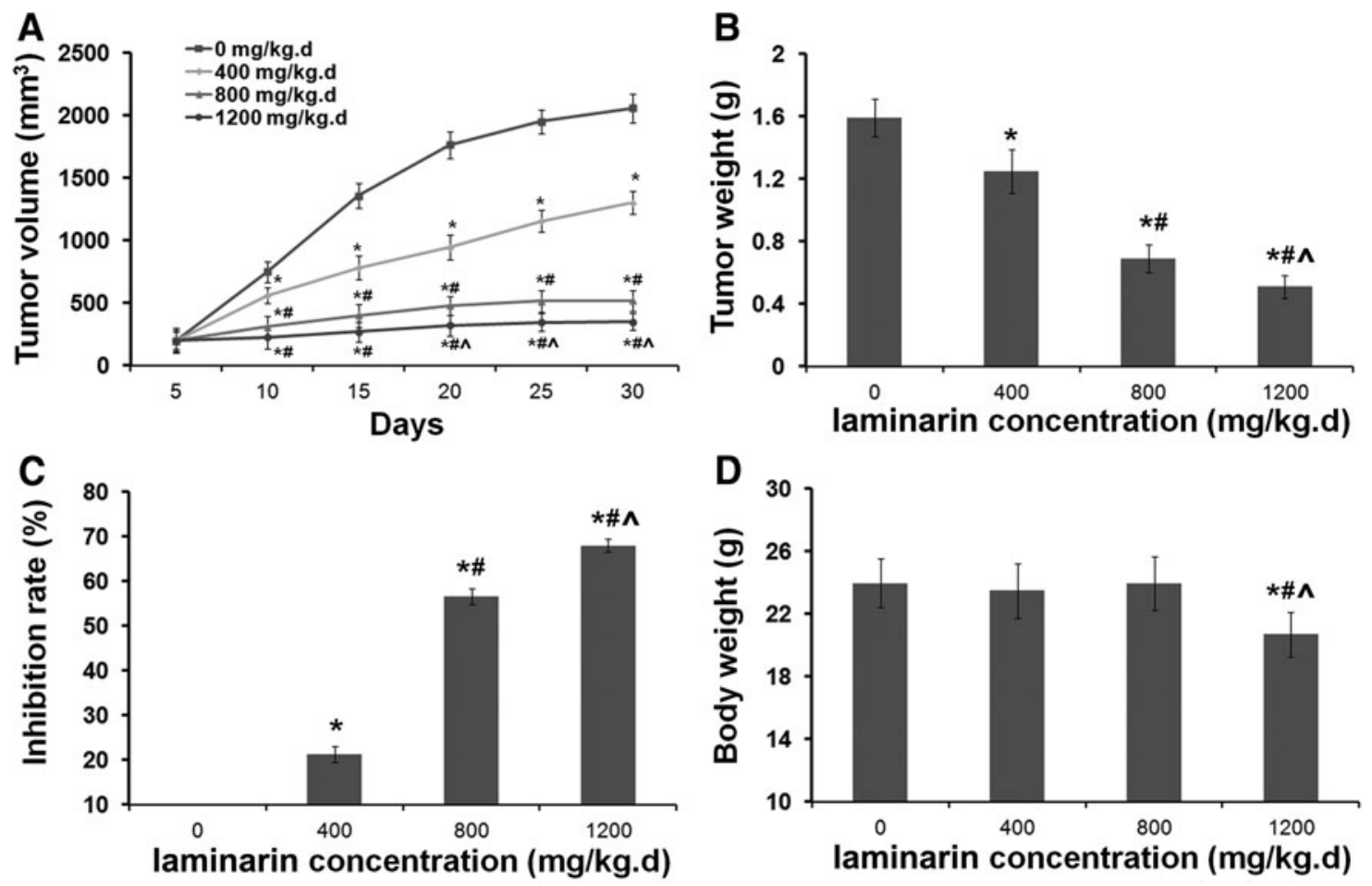

FIG. 3. The tumor growth in Hepa 1-6 tumor-bearing mice. (A) Tumor volume of mice injected with laminarin at different concentrations and time points. (B) Tumor weight of mice injected with laminarin at different concentrations for $30 \mathrm{~d}$. (C) Inhibition rate of laminarin at different concentrations. (D) Body weight of mice injected with laminarin at different concentrations for $30 \mathrm{~d}$. *, \# and ^Represent significant differences with $p<0.05$ when compared with 0 , 400, and $800 \mathrm{mg} / \mathrm{kg} \cdot \mathrm{d}$ laminarin, respectively.

The antitumor roles of $\beta$-glucan have been identified by some studies. For example, $\beta$-glucan from Lentinus edodes inhibits tumor growth in mice by suppressing the proliferation and enhancing the apoptosis of MCF-7 breast cancer cells. ${ }^{18}(1 \rightarrow 3)$ - $\beta$-D-glucan from Saccharomyces cerevisiae significantly decreases the volume and weight of S180 tumors in mice. ${ }^{19} \beta$-glucan from the Maitake mushroom induces the apoptosis of prostate cancer PC- 3 cells. ${ }^{20}$ Since laminarin is a 1,3- and 1,6-glycosidic bond-linked $\beta$-Dpolysaccharide, we suspected that laminarin may also have antitumor potential in HCC. In this study, the specific roles of laminarin in the proliferation and apoptosis of HCC cells were evaluated. We found that $48 \mathrm{~h}$ of laminarin treatment significantly decreased the viability and increased the apoptosis rates of Bel-7404 and HepG2 cells in a dosedependent manner. These findings illustrate that laminarin exerts antitumor effects similar to those of $\beta$-glucan. Moreover, it looks as though the effect of laminarin levels off at $35 \mathrm{mg} / \mathrm{mL}$ concentration. It shows that the cells have a certain threshold of sensitivity to polysaccharide drugs. When the dose exceeds this threshold, its effect does not change significantly. Of note, and different from the $\beta$-glucan or $(1 \rightarrow 3)-\beta$-D-glucan, an even higher dose of laminarin $(35 \mathrm{mg} / \mathrm{mL})$ was used in our experiment. It appears that the number and structure of glycosidic bonds in polysaccharides will affect their function. The activity of glucans with 1,3- and 1,6- branches requires higher doses than that of glucans with 1,3- branch or no branch.
In addition, previous studies have proved that laminarin inhibits the colony formation of CC DLD-1 cells and promotes the apoptosis of CC HT-29 cells. ${ }^{10,11}$ Consistent with its roles in CC cells, laminarin can also inhibit the proliferation and promote the apoptosis of HCC cells in vitro. To further identify the antitumor effects of laminarin in HCC in vivo, laminarin was injected into Hepa 1-6 tumor-bearing mice. We found that the injection of laminarin significantly decreased the tumor volume and tumor weight in a dose-dependent manner. These findings are consistent with a previous study on $(1 \rightarrow 3)-\beta$-D-glucan mentioned earlier and further illustrate that laminarin can inhibit HCC tumor growth in vivo. However, excessive laminarin may also be harmful since the body weights of mice were significantly decreased by the injection with $1200 \mathrm{mg} / \mathrm{kg} \cdot \mathrm{d}$ laminarin.

The regulatory mechanisms of laminarin in tumors are complex and have been suggested to be associated with ErbB2 phosphorylation, mitochondria, and the death receptor pathway in CC cells. ${ }^{9,10,21}$ In this study, the expression of a prognostic marker of HCC, SMP-30, was detected. We found that the treatment with laminarin significantly increased the expression of SMP-30 in Bel-7404 and HepG2 cells but not in LO2 cells, compared with the expression in the control cells. These findings illustrate that laminarin specifically upregulates SMP-30 in HCC cells. Previous studies have proved that overexpression of SMP30 inhibits the proliferation of HepG2 cells and blocks cells in G1 and G2/M phase. ${ }^{15}$ Therefore, we suspect that laminarin may 


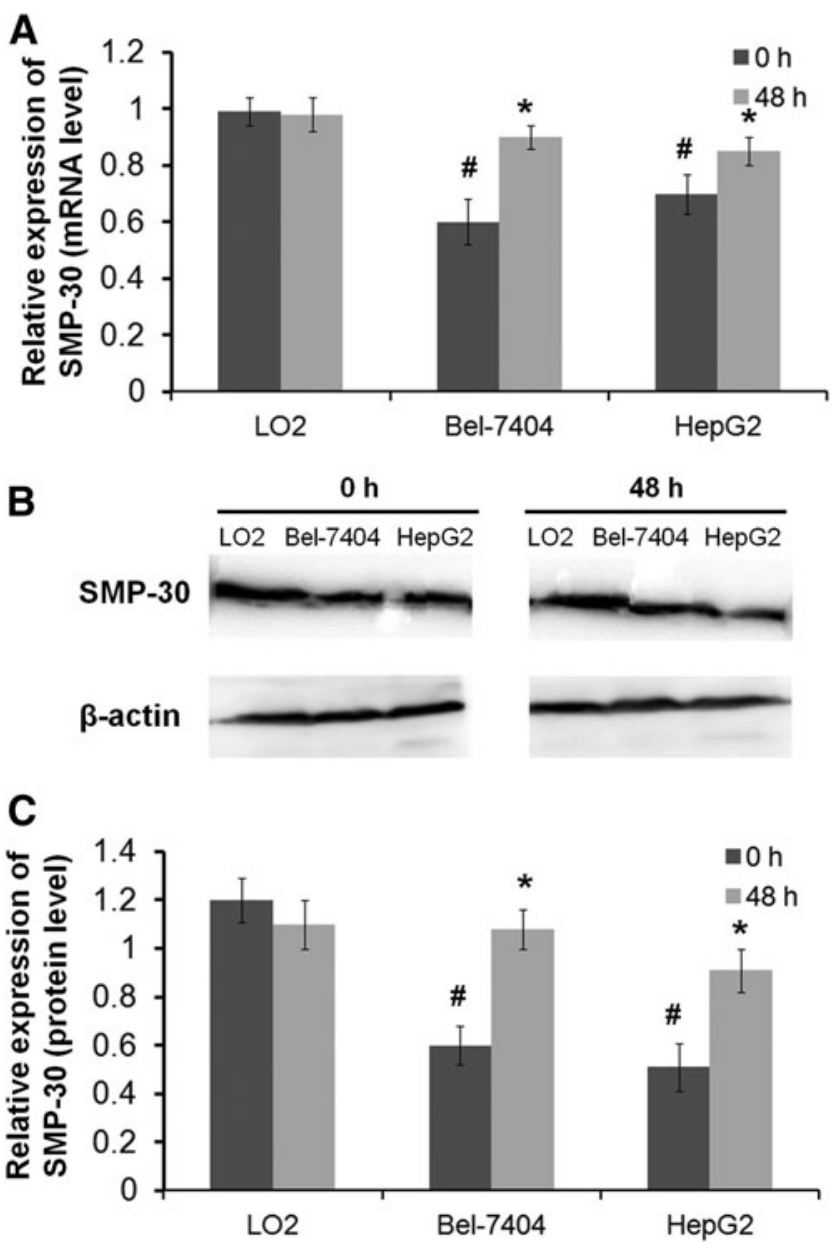

FIG. 4. The expression of senescence marker protein-30 (SMP-30) in LO2, Bel-7404, and HepG2 cells. (A) Relative expression of SMP-30 at the mRNA level. (B) Protein bands of SMP-30 and $\beta$-actin. (C) Relative expression of SMP-30 at the protein level. *Represents a significant difference with $p<0.05$ when compared with LO2 cells; \# represents a significant difference with $p<0.05$ when compared with $0 \mathrm{~h}$.

inhibit the proliferation and promote the apoptosis of HCC cells by upregulating SMP-30. In addition, the data showed that the effect of laminarin to upregulate SMP-30 in Bel7404 cells is more obvious than that in HepG2 cells. Considering that the Bel-7404 cells were mainly in the late phase of apoptosis and the HepG2 cells were mainly in the early phase of apoptosis, we speculated that SMP-30 is mainly directed to the late apoptosis.

In conclusion, laminarin significantly inhibited proliferation and promoted apoptosis in Bel-7404 and HepG2 cells in vitro, and it significantly suppressed tumor growth in Hepa 1-6 tumor-bearing mice in vivo. The antitumor effects of laminarin in HCC were closely associated with the upregulation of SMP-30. Laminarin may be a promising therapeutic agent for HCC. However, the specific effects of laminarin on the invasion and migration of HCC cells, as well as the metastasis of tumors in vivo, are still unclear, and further studies are still needed.

\section{Conclusions}

Laminarin inhibited the proliferation of Bel-7404 and HepG 2 cells and the growth of tumor in Hepa 1-6 tumorbearing mice by upregulating SMP-30.

\section{Disclosure Statement}

No competing financial interests exist.

\section{Funding Information}

This work was supported by the Natural Science Foundation of Guangxi (2016GXNSFAA380267, 2017GXNSFA A198079, 2018GXNSFAA281071, and 2018GXNSFAA13 8144) and the Guangxi First-class Discipline Project for Basic Medicine Sciences (GXFCDP-BMS-2018).

\section{References}

1. Han YF, Zhao J, Ma LY, et al. Factors predicting occurrence and prognosis of hepatitis-B-virus-related hepatocellular carcinoma. World J Gastroenterol 2011;17: 4258.

2. Perz JF, Armstrong GL, Farrington LA, et al. The contributions of hepatitis $B$ virus and hepatitis $C$ virus infections to cirrhosis and primary liver cancer worldwide. J Hepatol 2006;45:529.

3. Lamarca A, Mendiola M, Barriuso J. Hepatocellular carcinoma: Exploring the impact of ethnicity on molecular biology. Crit Rev Oncol Hematol 2016;105:65.

4. Fu J, Zhang JY, Wang FS. Tamibarotene: A new hope for therapeutic efficacy in hepatocellular carcinoma patients. Hepatol Int 2014;8:1.

5. Singal AG, Nehra M, Adams-Huet B, et al. Detection of hepatocellular carcinoma at advanced stages among patients in the HALT-C Trial: Where did surveillance fail? Am J Gastroenterol 2013;108:425.

6. Dhir M, Melin AA, Douaiher J, et al. A review and update of treatment options and controversies in the management of hepatocellular carcinoma. Ann Surg 2016; 263:1112.

7. Kawada M, Atsumi S, Wada SI, et al. Novel approaches for identification of anti-tumor drugs and new bioactive compounds. J Antibiot 2018;71:39.

8. Zvyagintseva TN, Shevchenko NM, Nazarova IV, et al. Inhibition of complement activation by water-soluble polysaccharides of some far-eastern brown seaweeds. Comp Biochem Physiol C Toxicol Pharmacol 2000;126: 209.

9. Ji YB, Ji CF, Zhang H. Laminarin induces apoptosis of human colon cancer LOVO cells through a mitochondrial pathway. Molecules 2012;17:9947.

10. Park HK, Kim IH, Kim J, et al. Induction of apoptosis and the regulation of ErbB signaling by laminarin in HT29 human colon cancer cells. Int J Mol Med 2013;32: 291.

11. Menshova RV, Ermakova SP, Anastyuk SD, et al. Structure, enzymatic transformation and anticancer activity of branched high molecular weight laminaran from brown alga Eisenia bicyclis. Carbohydr Polym 2014;99: 101. 
12. Nishijima K, Ohno T, Amano A, et al. Bone degeneration and its recovery in SMP30/GNL-knockout mice. J Nutr Health Aging 2017;21:573.

13. Kondo Y, Ishigami A. Involvement of senescence marker protein-30 in glucose metabolism disorder and nonalcoholic fatty liver disease. Geriatr Gerontol Int 2016; $16: 4$.

14. Mo Z, Zheng S, Lv Z, et al. Senescence marker protein 30 (SMP30) serves as a potential prognostic indicator in hepatocellular carcinoma. Sci Rep 2016;6:39376.

15. Zhang SC, Liang MK, Huang GL, et al. Inhibition of SMP30 gene expression influences the biological characteristics of human Hep G2 cells. Asian Pac J Cancer Prev 2014;15:1193.

16. Lee LJ, Chen CH, Yao G, et al. Quality of life in patients with hepatocellular carcinoma received surgical resection. J Surg Oncol 2007;95:34.
17. Kojima-Yuasa A, Huang X, Matsui-Yuasa I. Synergistic anticancer activities of natural substances in human hepatocellular carcinoma. Diseases 2015;3:260.

18. $\mathrm{Xu} \mathrm{H}, \mathrm{Zou} \mathrm{S}, \mathrm{Xu} \mathrm{X}$. The $\beta$-glucan from Lentinus edodes suppresses cell proliferation and promotes apoptosis in estrogen receptor positive breast cancers. Oncotarget 2017; 8:86693.

19. Mo L, Chen Y, Li W, et al. Anti-tumor effects of $(1 \rightarrow 3)$ - $\beta$-D-glucan from Saccharomyces cerevisiae in S180 tumor-bearing mice. Int J Biol Macromol 2017;95: 385.

20. Fullerton SA, Samadi AA, Tortorelis DG, et al. Induction of apoptosis in human prostatic cancer cells with betaglucan (Maitake mushroom polysaccharide). Mol Urol 2000;4:7.

21. Ji CF, Ji YB. Laminarin-induced apoptosis in human colon cancer LoVo cells. Oncol Lett 2014;7:1728. 